\title{
Middlebrook 7H12 Growth Medium
}

National Cancer Institute

\section{Source}

National Cancer Institute. Middlebrook 7 H12 Growth Medium. NCI Thesaurus. Code C127520.

A liquid growth medium modified from the Middlebrook $7 \mathrm{H} 9$ broth by the addition of the following: bovine serum albumin, casein hydrolysate, catalase, and 14C-labelled palmitic acid. 